\title{
Leakage Current Assessment Using Correlation Coefficient and Principal Component Analysis on The Eight-Month Naturally Coastal Contaminated Outdoor Porcelain Insulator
}

\author{
Waluyo $^{1}$, Parouli M. Pakpahan ${ }^{2}$, Suwarno $^{2}$, Maman A. Djauhari ${ }^{3}$ \\ ${ }^{1}$ Doctoral Student, School of Electrical Engineering and Informatics (STEI) ITB, Bandung \\ Academic Staff, Electrical Engineering Department, ITENAS, Bandung \\ Email: waluyo@students.itb.ac.id \\ ${ }^{2}$ Academic Staff, School of Electrical Engineering and Informatics (STEI) ITB, Bandung \\ ${ }^{3}$ Academic Staff, Department of Mathematics, ITB, Bandung
}

\begin{abstract}
This manuscript presents the experimental results of eight months naturally coastal contaminated outdoor porcelain insulator. The conducted experiments were leakage current and applied high voltage measurements, in the hermetically sealed chamber, where temperature, humidity, pressure and applied voltage could be adjusted and measured simultaneously. The leakage current waveforms were analyzed using FFT and the relation to other parameters were analyzed using correlation coefficient and principal component analysis. On high humidity, the leakage current waveforms tended to approach pure sinusoides, and the amplitudes tended to rise. Based on the correlation coefficient, the relative humidity influenced to leakage current amplitudes and phase angle as 0.60 and -0.68 respectively. Whereas, using PCA, the humidity close to power factor, and the phase angle close to THD and applied voltage. However, the phase angle opposites to the humidity. The extracted for 2 and 3 components are $74.5 \%$ and $85.3 \%$ respectively.
\end{abstract}

Keywords: correlation coefficient, harmonic, humidity, insulator, leakage current, phase angle, PCA

\section{INTRODUCTION}

Overhead transmission or distribution lines are widely used in present power system to transmit electric power from generation stations to customer points. Their proper function depends to a large extent on the insulation system with the supporting structures [1]. The performance of outdoor insulators, as main insulating materials, is influenced by many parameters. Some of parameters are environmental contamination, humidity, temperature, pressure and applied voltage.

The pollution flashover process of insulators is greatly influenced by the insulator's surface properties. Two main surface conditions are hydrophilic and hydrophobic. A hydrophilic surface is generally associated with ceramic insulators, such as porcelain, whereas a hydrophobic surface is associated with polymeric insulators. Under wetting conditions, hydrophilic surfaces will wet out completely so that an electrolyte film covers the insulator [2].

For better understanding of insulator pollution, wetting and the flashover process, some terms should be studied. Some terms related to this case are the local climate and environmental conditions surrounding the insulator with emphasis on wetting, pollution sources and type of pollution, and leakage current flowing over the surface of insulator [2]

Note: Discussion of this paper must be submitted before June, $1^{\text {st }} 2008$. The proper discussion will be published in Electrical Engineering Journal volume 8, number 2, September 2008.
The performance of insulator under contaminated conditions is the underlying factor that determines insulation design for outdoor application. Contamination has a role to play in every outdoor insulator application. This fact was recognized since the very beginning of outdoor power delivery. There are instances where discrepancies between laboratory predictions and field experience arise. Thus, it is important to have a good understand the advantages and limitations of laboratory testing, in order to develop more sensible tests for ceramic and nonceramic insulators [3].

One of typical source of insulator pollutants is marine or coast [4]. Indonesia has the longest of coastal line in the world. Usually, a coastal region is passed through by electric power transmission or distribution lines, including switchyard. Thus, it is important to take a sample of polluted porcelain insulator from a place near a coast for research.

The objectives of research are to obtain the correlation of leakage current properties among relative humidity, temperature, pressure and applied voltage on the eight-month coastal polluted insulator. The leakage current is one parameter to make assessment of outdoor insulator performance. These property parameters are leakage current amplitudes, waveforms and phase angles. The relation among the properties to environmental parameters are analyzed using correlation coefficient and principal component 
analysis of multivariate statistical tool. Thus, it can be understood each variable influence to another.

\section{EXPERIMENTAL AND ANALYSIS METHODS}

These experiments were conducted on a $20 \mathrm{kV}$ coastal contaminated outdoor porcelain insulator. The contaminated insulator has been installed at PLN switchyard of Pangandaran, West Java, just around $600 \mathrm{~m}$ from the beach, as sample of coastal contamination, on December $15^{\text {th }}, 2006$, and then taken on August 21 2007.

The insulator was tested in a hermetically sealed chamber, where temperature, humidity, pressure and applied voltage could be adjusted and measured simultaneously. The size of the chamber was $120 \mathrm{~cm}$ $\mathrm{x} 120 \mathrm{~cm}$ x $150 \mathrm{~cm}(\mathrm{WxDxH})$. The measurements of leakage current and applied high voltage waveforms used a $100 \mathrm{MHz}$ two-channel storage digital oscilloscope. The measured data could be recorded and transferred to a computer using USB (Universal Serial Bus) and OpenChoice Desktop software. They could be saved in softcopy form. The data could be read and saved in Excel and Bitmap forms. The schematic diagram of experimental setup is shown on Figure 1.

Furthermore the data of leakage current waveforms were analyzed by fast Fourier transform using OriginPro V7.5 software. The total harmonic distortion (THD) is defined as the total ratio of the harmonic components and the fundamental which can be expressed as below [5].

$T H D=\frac{\sqrt{\sum_{n=2}^{\tilde{N}} I_{n}^{2}}}{I_{1}}$

Thus, the frequency spectra were obtained on some conditions of insulator. These implementations used the Danielson-Lanczos method [6]. Whereas the relation of leakage currents to environmental parameters were analyzed using matrix of correlation coefficient of multivariate statistical tools. The correlation coefficient is derivation of covariance matrix to understand how much level of correlation among parameters base on these research results, as follows $[7,8]$

$$
\operatorname{Cov}(X, Y)=\frac{1}{n} \sum_{j=1}^{n}\left(x_{j}-\mu_{x}\right)\left(y_{j}-\mu_{y}\right)
$$

Thus, the components of correlation matrix as below.

$$
\rho_{x, y}=\frac{\operatorname{Cov}(X, Y)}{\sigma_{x} \cdot \sigma_{y}}
$$

The values of correlation matrix components are between -1 until 1 . If a value close to -1 , it represents that one parameter highly influences to another, but it is reciprocal property. Otherwise, if a value close to 1 , it reveals that one parameter highly proportional influences to another. Finally, if a value close to zero, it is minor in dependency.

Another way to assess among parameter correlations is using principal component analysis (PCA) $[9,10,11]$. If a set of data is presented in matrix $X$, the main algorithm of PCA involves some steps as below.

- Determine the mean components of matrix X, those related by

$$
\bar{x}_{l}=\frac{1}{n} \sum_{k=1}^{n} x_{1, k}
$$

- Determine covariance matrix using equation of

$$
C=X * X^{T}
$$

- Determine eigen value and eigen vector of covariance matrix using equation of

$$
C Q=\lambda Q
$$

where $\lambda$ are eigen values and $Q$ are eigen vectors. Base on the eigen values, it is plotted their scatters in two and three dimensions. Thus, the nearness of

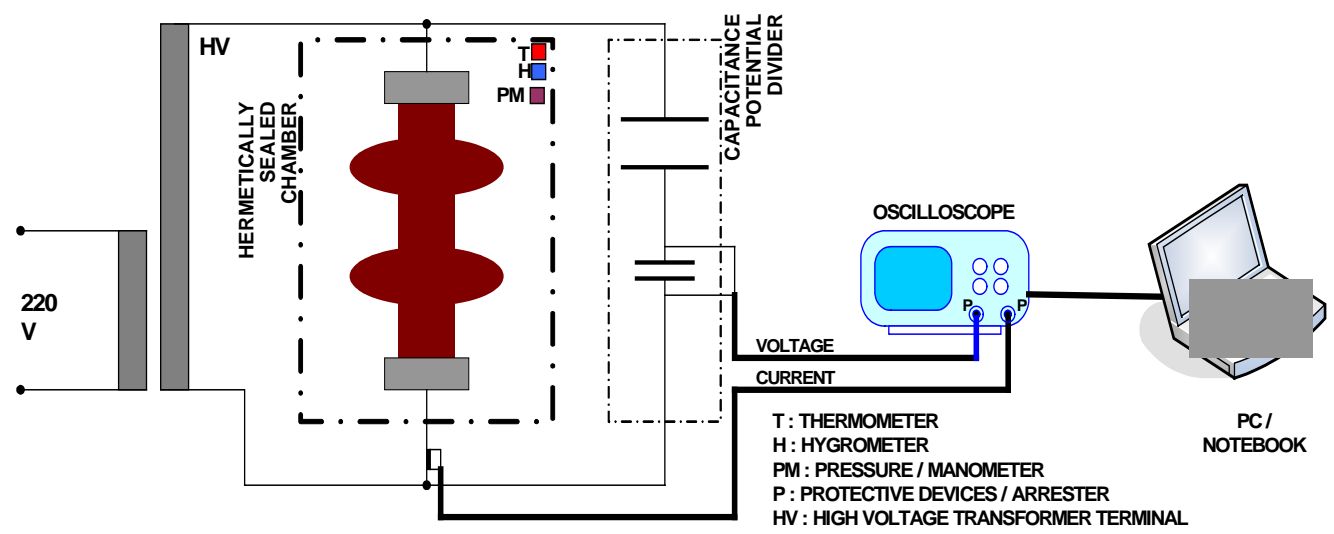

Figure 1. Schematic diagram of experimental setup 
parameters indicates the correlation level on such parameters.

\section{RESULTS AND DISCUSSION}

Actually, there were many data on these experiments, with various humidity, temperature, pressure and applied voltage amplitudes. However, in this manuscript it is revealed some typical waveforms of result data. Generally, the data could be obtained in two forms of file, spreadsheet data and bitmap drawing files.

In this manuscript, it is presented two significant conditions, dry and wet, that indicated by low and high relative humidities.

In dry hermetically sealed chamber condition, the waveform of typical leakage current measurement in bitmap form is shown on Figure 2. This waveform was obtained on condition of relative humidity, temperature, pressure and maximum applied voltage were $71 \%, 42.4^{\circ} \mathrm{C}, 0.2 \mathrm{kPa}$ and $55.4 \mathrm{kV}$ respectively.

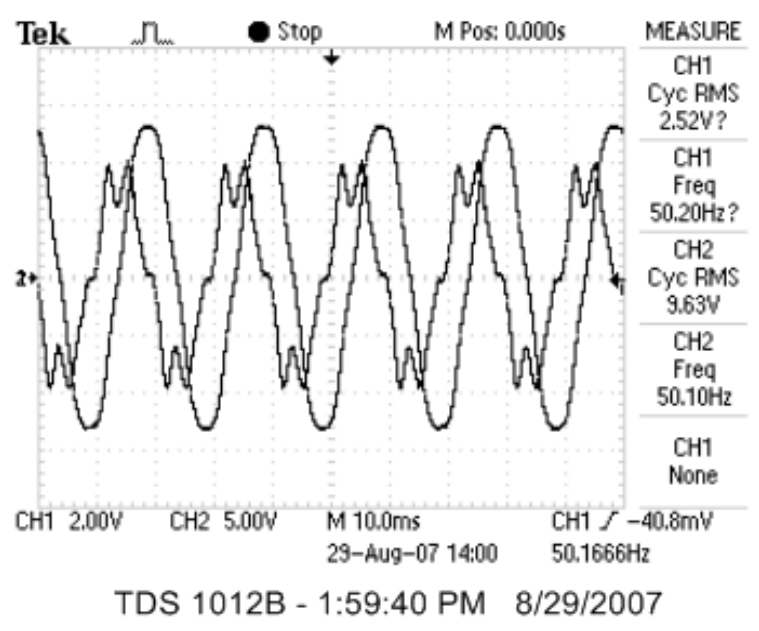

Figure 2. Bitmap form of applied voltage and leakage current waveforms of dry polluted insulator

Whereas Figure 3 is Excel graphical form of applied voltage and leakage current waveforms of polluted insulator on that condition. The applied voltage is pure sinusoidal waveform, that the magnitude values are mentioned on the right side. Otherwise, the magnitude values of leakage current wave are indicated on the left side. Thus, in dry condition, the pollutants stuck on porcelain insulator surface do not influence leakage current significantly. In this case, the phase difference between leakage current and applied voltage waveforms is 74.9 degree. This is very capacitive. Based on this leakage current waveform, it will be analyzed the frequency spectrum using fast Fourier transform.

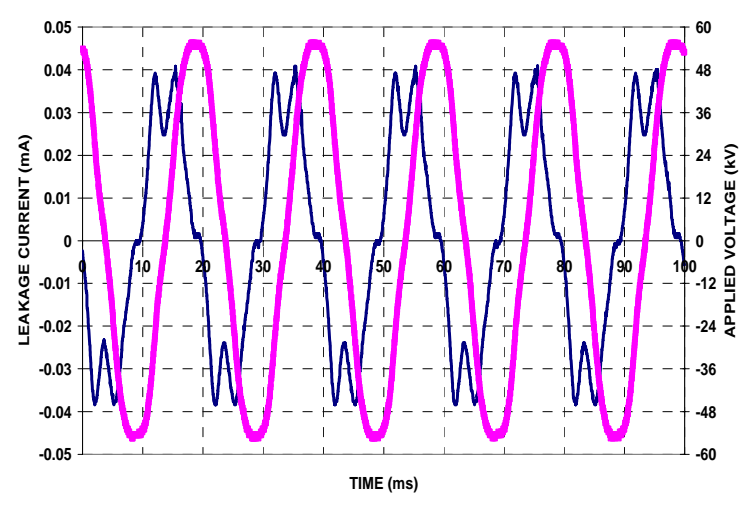

Figure 3. Excel graphical form voltage and leakage current waveforms of dry polluted insulator

Figure 4 shows the frequency spectrum of leakage current waveform of Figure 3. On this condition, the first to thirteenth odd harmonics are $80.15 \%, 0.97 \%$, $17.94 \%, 5.2 \%, 0.27 \%, 1.6 \%, 0.39 \%$ respectively compared to leakage current amplitude. The third harmonic is very small, so that it still operates normally. Otherwise, the total harmonic distortion (THD) is $23 \%$, so that it is also normal condition.

On other condition, Figure 5 shows bitmap form of leakage current and applied voltage waveforms on polluted insulator due to $99 \%, 26^{\circ} \mathrm{C},-0.8 \mathrm{kPa}$ and $10.9 \mathrm{kV}$ maximum applied voltage. Furthermore, Figure 6 is its Excel graphical form. This is as sample of wet condition.

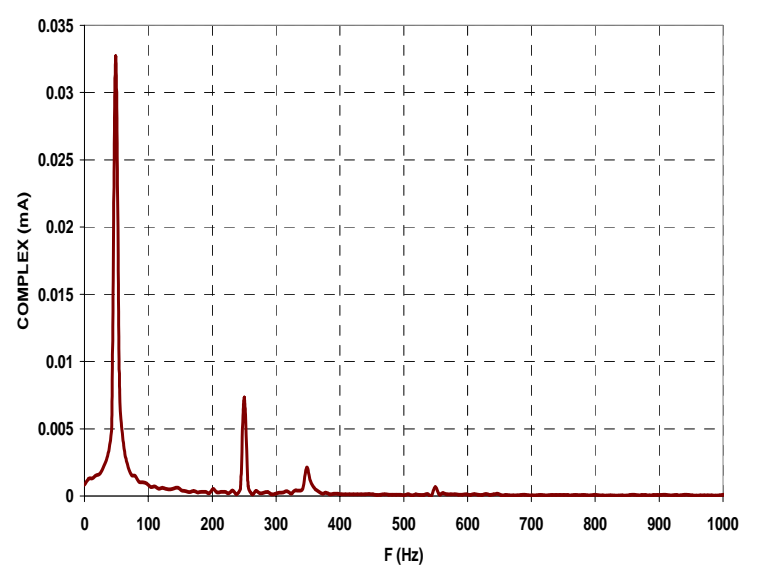

Figure 4. Frequency spectrum of leakage current waveforms of Figure 3

The applied voltage is pure sinusoidal waveform, that the magnitude values are mentioned on the right side. Otherwise, the magnitude values of leakage current wave are indicated on the left side. In this condition, the phase difference between leakage current and applied voltage waves is 12.2 degree. This drastically reduces rather than that the previous new-clean, or the dry contaminated condition ones. 


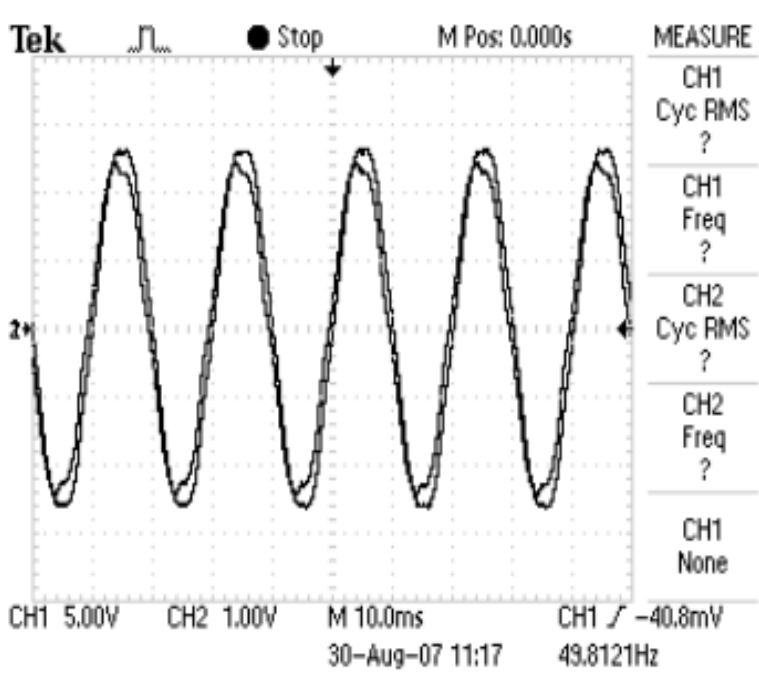

TDS 1012B - 11:16:25 AM 8/30/2007

Figure 5. Bitmap form of voltage and leakage current waveforms of wet polluted insulator

Based on this leakage current waveform, it will be analyzed the frequency spectrum using fast Fourier transform.

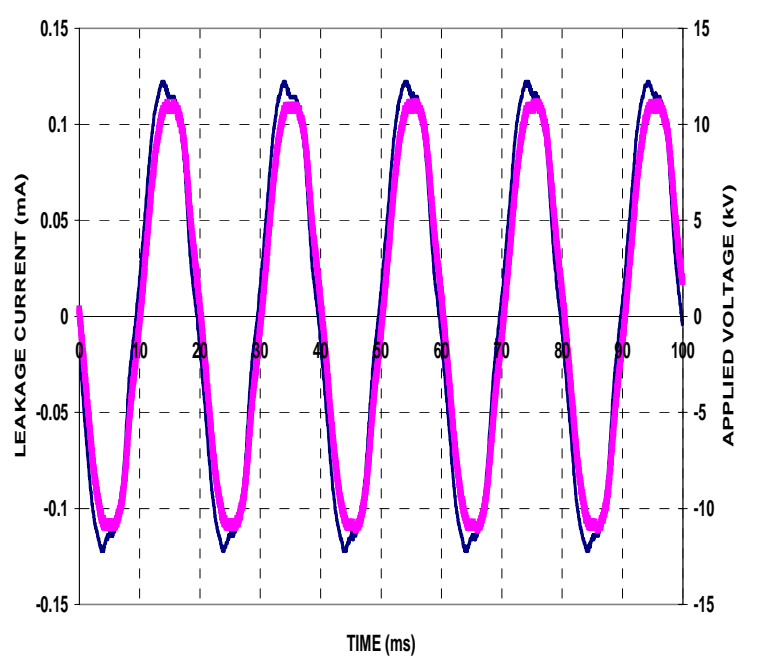

- LEAKAGE CURRENT (mA) - APPLIED VOLTAGE $(\mathrm{kV})$

Figure 6. Excel graphical form of voltage and leakage current waveforms of wet polluted insulator

Figure 7 represents the frequency spectrum of leakage current waveform on Figure 6. The first to thirteenth odd harmonics are $95.15 \%, 1.11 \%, 5.1 \%$, $0.97 \%, \quad 0.52 \%, \quad 0.77 \%$ and $0.36 \%$ respectively compared to leakage current amplitude. The total harmonic distortion (THD) is only $6 \%$, due to the leakage current waveform tends to close pure sinusoidal wave. This is the most conductive condition among previous conditions, indicated by small total harmonic distortion.

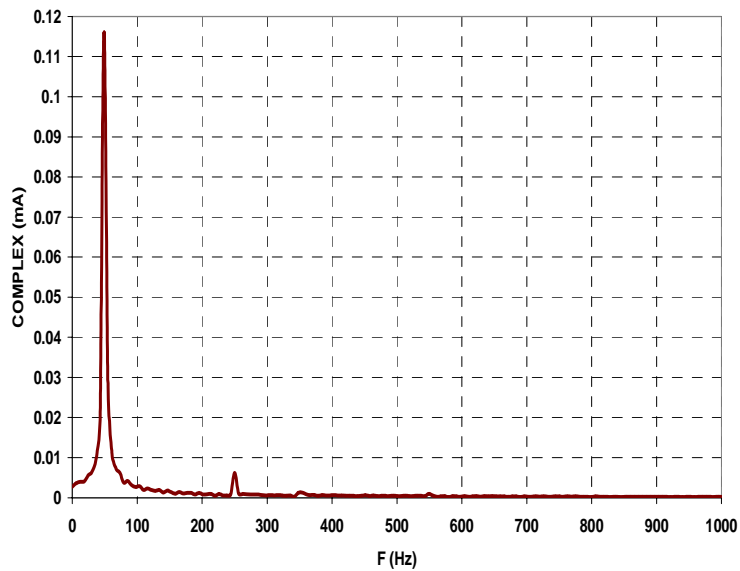

Figure 7. Frequency spectrum of leakage current waveforms of Figure 6

Table 1 reveals the complete summary experimental data on the measurements of coastal polluted porcelain insulator. First to last columns are maximum applied voltage $(\mathrm{kV})$, maximum leakage current (micro ampere), relative humidity (\%), temperature (centigrade), pressure (kPA), phase difference between leakage current and applied voltage waves (degree), cosine of phase difference, first to thirteenth odd harmonics (micro ampere), and total harmonic distortion (THD) respectively. The positive pressure means the chamber was compressed, and the negative pressure means the chamber was sucked, using electric pumps. Generally, the phase difference between leakage current and applied voltage will reduce as the relative humidity increases. The levels of correlation among parameters on coastal polluted porcelain insulator are indicated by Table 2 .

Table 2 express the correlation matrix among variables of measurements on the coastal polluted insulator. Based on this correlation matrix, the relative humidity considerably influences to the maximum leakage current magnitude and the phase difference between leakage current and applied voltage. These are $60 \%$ and $-68 \%$ respectively. This gives explanation that the relative humidity enhanced the maximum leakage current very significantly. This is also supported by the negative value of correlation component between applied voltage and leakage current. This indicates that the leakage current is dominantly influenced by relative humidity, rather than applied voltage, although the leakage current existence was caused by applied voltage technically. As addition, the relative humidity influenced to phase difference also considerably, that was $-68 \%$. Generally, the phase difference would reduce as the relative humidity increased. 
Table 1 . The summary of polluted porcelain insulator experimental data

\begin{tabular}{|c|c|c|c|c|c|c|c|c|c|c|c|c|c|c|}
\hline $\begin{array}{l}V_{\max } \\
(\mathrm{kV})\end{array}$ & $\begin{array}{l}\mathrm{I}_{\max } \\
(\mathrm{uA})\end{array}$ & $\begin{array}{c}\mathrm{H} \\
(\%)\end{array}$ & $\begin{array}{c}\mathrm{T} \\
\left({ }^{\circ} \mathrm{C}\right)\end{array}$ & $\begin{array}{c}\mathrm{P} \\
(\mathrm{kPA})\end{array}$ & $\begin{array}{c}\text { PHA } \\
\text { (DEG) }\end{array}$ & $\begin{array}{c}\operatorname{COS} \\
\text { (PHA) }\end{array}$ & $\begin{array}{c}\mathrm{Hl} \\
\text { (u.A) }\end{array}$ & $\begin{array}{c}\mathrm{H} 3 \\
(\mathrm{uA})\end{array}$ & $\begin{array}{c}\mathrm{H} 5 \\
(\mathrm{uA})\end{array}$ & $\begin{array}{c}\mathrm{H}^{7} \\
(\mathrm{uA})\end{array}$ & $\begin{array}{c}\mathrm{H} 9 \\
\text { (u.A) }\end{array}$ & $\begin{array}{l}\text { H1l } \\
(\mathrm{uA})\end{array}$ & $\begin{array}{l}\mathrm{H} 13 \\
(\mathrm{uA})\end{array}$ & IHD \\
\hline 25.2 & 26.4 & 68 & 25.2 & 0 & 60.7 & 0.49 & 21.93 & 0.248 & 3.11 & 0.79 & 0.297 & 0.580 & 0.133 & 0.15 \\
\hline 51.2 & 55.2 & 68 & 25.3 & 0 & 59.9 & 0.50 & 44.57 & 0.579 & 7.96 & 2.29 & 0.250 & 0.796 & 0.187 & 0.19 \\
\hline 66.4 & 71.2 & 68 & 25.2 & 0 & 59.7 & 0.50 & 57.74 & 0.696 & 11.12 & 2.73 & 0.213 & 0.835 & 0.2 & 0.20 \\
\hline 63.0 & 67.2 & 68 & 25.2 & 0 & 59.6 & 0.51 & 53.93 & 0.724 & 10.30 & 2.65 & 0.222 & 0.823 & 0.205 & 0.20 \\
\hline 52.1 & 54.4 & 68 & 25.2 & 0 & 61.2 & 0.48 & 43.51 & 0.590 & 8.17 & 2.39 & 0.139 & 0.810 & 0.176 & 0.20 \\
\hline 48.7 & 48.8 & 68 & 25.3 & 0 & 62.3 & 0.46 & 40.07 & 0.591 & 7.15 & 2.09 & 0.206 & 0.858 & 0.175 & 0.19 \\
\hline 44.5 & 45.6 & 68 & 25.3 & 0 & 62.0 & 0.47 & 36.87 & 0.532 & 6.48 & 1.88 & 0.219 & 0.842 & 0.173 & 0.19 \\
\hline 52.1 & 49.6 & 68 & 28.5 & 0.2 & 64.8 & 0.43 & 40.70 & 0.475 & 7.50 & 2.47 & 0.208 & 0.842 & 0.218 & 0.20 \\
\hline 52.1 & 47.2 & 68 & 30.7 & 0.0 & 65.8 & 0.41 & 38.54 & 0.467 & 7.39 & 2.46 & 0.143 & 0.767 & 0.227 & 0.20 \\
\hline 54.6 & 44.8 & 67 & 32.6 & 0.4 & 71.0 & 0.33 & 36.18 & 0.145 & 7.19 & 2.22 & 0.087 & 0.734 & 0.131 & 0.21 \\
\hline 54.6 & 40.8 & 67 & 35.6 & 0.2 & 71.0 & 0.33 & 34.69 & 0.212 & 7.02 & 2.27 & 0.059 & 0.714 & 0.152 & 0.21 \\
\hline 55.4 & 40.8 & 70 & 37.3 & 0.0 & 72.7 & 0.30 & 33.64 & 0.403 & 7.29 & 2.27 & 0.127 & 0.790 & 0.171 & 0.23 \\
\hline 55.4 & 41.6 & 70 & 39.9 & 0.0 & 74.3 & 0.27 & 32.73 & 0.370 & 7.28 & 2.22 & 0.089 & 0.763 & 0.149 & 0.23 \\
\hline 55.4 & 40.8 & 71 & 42.4 & 0.2 & 74.9 & 0.26 & 32.71 & 0.395 & 7.32 & 2.12 & 0.117 & 0.653 & 0.158 & 0.23 \\
\hline 55.4 & 39.2 & 70 & 45.0 & 0.0 & 74.3 & 0.27 & 32.66 & 0.410 & 7.40 & 2.12 & 0.088 & 0.745 & 0.172 & 0.24 \\
\hline 55.4 & 40.8 & 70 & 43.9 & -2.0 & 76.6 & 0.23 & 32.49 & 0.409 & 7.34 & 2.15 & 0.096 & 0.648 & 0.157 & 0.24 \\
\hline 55.4 & 40.8 & 70 & 43.2 & -1.6 & 76.5 & 0.23 & 32.60 & 0.356 & 7.43 & 2.20 & 0.092 & 0.739 & 0.151 & 0.24 \\
\hline 55.4 & 40.8 & 69 & 42.3 & -1.2 & 76.5 & 0.23 & 32.58 & 0.399 & 7.38 & 2.24 & 0.059 & 0.796 & 0.152 & 0.24 \\
\hline 55.4 & 41.6 & 69 & 41.6 & -0.8 & 75.8 & 0.25 & 32.62 & 0.425 & 7.37 & 2.20 & 0.069 & 0.724 & 0.138 & 0.24 \\
\hline 55.4 & 41.6 & 69 & 40.5 & -0.4 & 76.3 & 0.24 & 32.61 & 0.352 & 7.40 & 2.19 & 0.036 & 0.753 & 163 & 0.24 \\
\hline 55.4 & 40.0 & 69 & 37.9 & -3.0 & 75.8 & 0.25 & 32.59 & 0.357 & 7.40 & 2.19 & 0.042 & 0.796 & 67 & 0.24 \\
\hline 55.4 & 40.8 & 69 & 36.6 & -4.0 & 75.8 & 0.25 & 32.57 & 0.410 & 7.35 & 2.19 & 0.031 & 0.797 & 177 & 0.24 \\
\hline 55.4 & 43.2 & 68 & 33.7 & -3.4 & 75 . & 0.25 & 32.54 & 0.373 & 7.22 & 2.23 & 0.020 & 0.729 & 0.194 & 0.23 \\
\hline 55.4 & 40.0 & 68 & 31.1 & 4.0 & 75.9 & 0.24 & 32.91 & 0.443 & 7.09 & 2.31 & 0.140 & 0.602 & 181 & 0.23 \\
\hline 55.4 & 40.0 & 68 & 31.1 & 3.0 & 75.4 & 0.25 & 32.84 & 0.394 & 7.08 & 2.43 & 0.102 & 0.646 & 0.209 & 0.23 \\
\hline 55.4 & 40.0 & 68 & 30.7 & 2.0 & 75.3 & 0.25 & 32.81 & 0.416 & 6.91 & 2.33 & 0.063 & 0.601 & 0.185 & 0.22 \\
\hline 55.4 & 39.2 & 68 & 30.5 & 1.6 & 75.9 & 0.24 & 32.83 & 0.426 & 6.94 & 2.35 & 0.127 & 0.595 & 0.176 & 0.22 \\
\hline 55.4 & 40.8 & 68 & 30.3 & 1.2 & 760 & 0.24 & 32.85 & 0.433 & 7.13 & 2.33 & 0.106 & 0.612 & 0.17 & 0.23 \\
\hline 55.4 & 39.2 & 68 & 30.1 & 0.8 & 76.2 & 0.24 & 32.80 & 0.431 & 7.19 & 2.33 & 0.117 & 0.627 & 0.244 & 0.23 \\
\hline 55.4 & 40.8 & 68 & 30.0 & 0.4 & 76.9 & 0.23 & 32.79 & 0.440 & 7.14 & 2.46 & 0.107 & 0.649 & 0.224 & 0.23 \\
\hline 26.5 & 194.0 & 76 & 24.5 & 0.2 & 23.0 & 0.92 & 182.64 & 2.320 & 12.32 & 4.31 & 1.570 & 1.720 & 0.693 & 0.07 \\
\hline 15.5 & 134.0 & 77 & 24.6 & 0.0 & 18.7 & 0.95 & 126.56 & 1.650 & 7.62 & 1.95 & 1.210 & 0.989 & 0.634 & 0.06 \\
\hline 15.5 & 178.0 & 78 & 25.0 & 0.0 & 14.4 & 0.97 & 166.90 & 2.190 & 9.69 & 1.95 & 1.110 & 1.090 & 0.809 & 0.06 \\
\hline 15.5 & 192.0 & 79 & 25.2 & 0.0 & 13.7 & 0.97 & 180.90 & 2.240 & 10.21 & 2.11 & 1.300 & 1.200 & 0.822 & 0.06 \\
\hline 10.8 & 158.0 & 83 & 25.5 & 0.0 & 12.1 & 0.98 & 151.58 & 1.870 & 6.99 & 1.14 & 0.805 & 0.754 & 0.548 & 0.05 \\
\hline 10.8 & 158.0 & 88 & 25.5 & 0.0 & 10.7 & 0.98 & 150.69 & 1.850 & 7.48 & 1.35 & 0.899 & 0.872 & 0.613 & 0.05 \\
\hline 10.8 & 158.0 & 89 & 25.5 & 0.0 & 11.5 & 0.98 & 149.87 & 1.890 & 7.68 & 1.41 & 0.960 & 0.757 & 0.68 & 0.05 \\
\hline 10.8 & 156. & 93 & 25.5 & 0.0 & 10.8 & 0.98 & 147.11 & 1.870 & 7.79 & 1.42 & 1.010 & 0.617 & 0.69 & 0.06 \\
\hline 10.8 & 148. & 97 & 25.0 & 0.0 & 11 . & 0.98 & 141.30 & 1.750 & 7.52 & 1.25 & 0.916 & 0.835 & 0.641 & 0.06 \\
\hline 10.8 & 146.0 & 98 & 25.7 & 0.0 & 11 & 0.98 & 138. & 1.700 & 7.25 & 1.24 & 0.822 & 0.975 & 0.541 & 0.06 \\
\hline 10.8 & 128.0 & 99 & 25.6 & -0.4 & 12 & 0.98 & 121.16 & 1.430 & 6.81 & 1.21 & 0.748 & 0.728 & 0.566 & 0.06 \\
\hline 11.1 & 122.0 & 99 & 25.5 & -1.4 & 13 & 0.97 & 115.45 & 1.400 & 6.69 & 1.17 & 0.664 & 0.670 & 0.553 & 0.06 \\
\hline 11.1 & 134.0 & 99 & 25.4 & -3.0 & 12.3 & 0.98 & 125.32 & 1.530 & 7.14 & 1.27 & 0.857 & 0.761 & 0.57 & 0.06 \\
\hline 11.1 & 118.0 & 98 & 25.2 & -4.0 & 13.0 & 0.97 & 110.95 & 1.260 & 6.45 & 1.28 & 0.758 & 0.897 & 0.497 & 0.06 \\
\hline 11.1 & 128.0 & 98 & 25.6 & -2.8 & 12.3 & 0.98 & 119.87 & 1.480 & 6.80 & 1.19 & 0.713 & 0.649 & 0.522 & 0.06 \\
\hline 10.9 & 120.0 & 99 & 25.8 & -1.6 & 13.6 & 0.97 & 113.99 & 1.410 & 6.50 & 1.36 & 0.745 & 1.030 & 0.456 & 0.06 \\
\hline 10.9 & 120.0 & 99 & 25.9 & -1.2 & 12.9 & 0.97 & 112.45 & 1.390 & 6.22 & 1.24 & 0.701 & 0.892 & 0.464 & 0.06 \\
\hline 10.9 & 122.0 & 99 & 26.0 & -0.8 & 12.2 & 0.98 & 116.08 & 1.360 & 6.23 & 1.18 & 0.639 & 0.942 & 0.436 & 0.06 \\
\hline 11.1 & 170.0 & 88 & 26.2 & 1.2 & 9.4 & 0.99 & 163.32 & 2.160 & 8.14 & 0.99 & 0.941 & 0.674 & 0.51 & 0.05 \\
\hline 10.9 & 166.0 & 87 & 26.3 & 2.8 & 9.8 & 0.99 & 158.12 & 2.020 & 7.66 & 0.93 & 1.030 & 0.786 & 0.492 & 0.05 \\
\hline 11.1 & 162.0 & 86 & 26.3 & 3.6 & 9.3 & 0.99 & 154.17 & 2.010 & 7.43 & 1.03 & 0.930 & 0.756 & 0.482 & 0.05 \\
\hline 11.1 & 150.0 & 86 & 26.3 & 4.0 & 10.8 & 0.98 & 144.74 & 1.810 & 6.98 & 0.93 & 0.922 & 0.898 & 0.424 & 0.05 \\
\hline 10.9 & 246.0 & 77 & 32.6 & 0.0 & 7.2 & 0.99 & 237.64 & 3.900 & 11.86 & 1.89 & 1.720 & 0.740 & 0.885 & 0.05 \\
\hline 11.1 & 186.0 & 70 & 36.8 & 0.2 & 10.1 & 0.98 & 177.68 & 2.560 & 9.06 & 1.19 & 1.130 & 0.871 & 0.626 & 0.05 \\
\hline 11.1 & 160.0 & 69 & 37.0 & 0.0 & & 0.98 & 151.09 & 2.190 & 7.84 & 1.16 & 1.060 & 0.750 & 0.625 & 0.06 \\
\hline 11.1 & 146.0 & 69 & 37.1 & & & & & 1.800 & & & & 920 & & 0.06 \\
\hline 11.1 & 124.0 & 69 & 37.7 & 0.0 & & & 117.24 & 1.460 & 6.39 & 1.22 & 0.628 & 0.832 & 536 & 0.06 \\
\hline 10.9 & 114.0 & 69 & 38.1 & 0.0 & & & & 1.420 & 5.87 & 1.24 & 0.708 & 0.877 & 519 & 0.06 \\
\hline 11.1 & 106.0 & 69 & 38.4 & 0.0 & & 0.96 & 99.27 & 1.260 & 5.65 & 1.08 & 0.471 & 0.732 & 0.512 & 0.06 \\
\hline 11.1 & 92.0 & 69 & 38.7 & 0.0 & 16.6 & 0.96 & 85.85 & 1.040 & 4.94 & 0.93 & 0.375 & 0.642 & 0.397 & 0.06 \\
\hline 11.1 & 84.0 & 69 & 39.0 & 0.0 & 17.3 & 0.95 & 79.20 & 0.867 & 4.71 & 0.87 & 0.394 & 0.776 & 0.389 & 0.06 \\
\hline 11.1 & 74.0 & 69 & 39.2 & 0.0 & 18.7 & 0.95 & 69.24 & 0.761 & 4.21 & 0.91 & 0.305 & 0.746 & 0.321 & 0.06 \\
\hline
\end{tabular}


Otherwise, the leakage current amplitude influences to phase angle very significantly, that is $-90 \%$. The

phase angle will reduce as the leakage current amplitude increases. Base on above explanation, the leakage current of polluted insulator is dominantly influenced by relative humidity. Furthermore, the leakage current magnitude influenced to phase angle very significantly. This indicates that on high relative humidity, the polluted insulator had resistivecapacitive non-linear characteristic property. This was occurred due to porcelain insulator property susceptible to pollution and humidity.

Generally, the leakage current amplitude will reduce as temperature rises. Technically, a high temperature existence would reduce the relative humidity, that the leakage current magnitude would consequently reduce. The high temperature also raised the phase angle. In other word, in high temperature, the insulators would be more capacitive rather than in low temperature, due to reducing of relative humidity. However, the rate of capacitive property to the temperature was higher on polluted insulator rather than that on new-clean insulator, yielded in previous measurements. Nevertheless, usually the magnitude values of phase angle were higher on the new-clean porcelain insulator rather than that on the polluted one.

Practically, on this range, the pressure did not influence to leakage current or phase angle. This is indicated by correlation coefficient of leakage current and phase angle correlated to pressure parameter as very low value, close to zero.

Otherwise, the data are analyzed by principal component analysis (PCA). PCA extracts the data to give most information, base on eigen values. In this case, it is presented in first two and three principal components. Figure 8 shows scree plot of eigen values for summary experimental data. The line of first to last eigen values is occured a sharp bend, so that this scree plot of data is very good, no indication of outlier.

The value of KMO (Keiser-Meyer-Olkin) measure of sampling adequacy is 0.761 , more than 0.5 , as indication that the used data have been adequate for analysis using PCA.

Figure 9 shows the scatter plot of first two principal components. The extracted information in this scatter plot is $78.94 \%$. It is shown, that relative humidity is close to power factor (COS_PHA). This means, the relative humidity $(\mathrm{H})$ rise so that it cause the power factor increase significantly. Reciprocally, it reduces phase difference between leakage current and applied voltage waves (PHA). This case is indicated by the phase angle opposites far away from relative humidity $(\mathrm{H})$. Little bit far from power factor, it is shown leakage current amplitude (Imax), first, third, ninth and thirteenth (H1, H3, H9 and H13) harmonics. This indicates that those harmonics are correlated to the amplitude of leakage current very significantly. The harmonics rose as the leakage current amplitude increased.

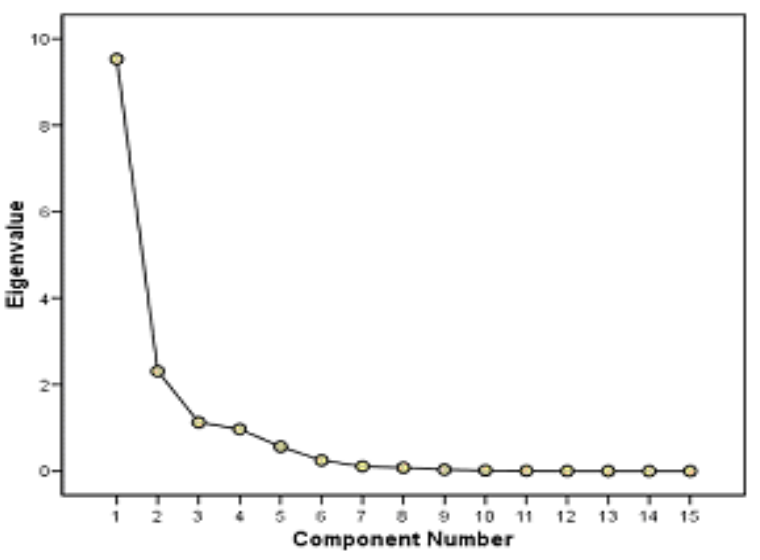

Figure 8 . Scree plot for summary experimental data

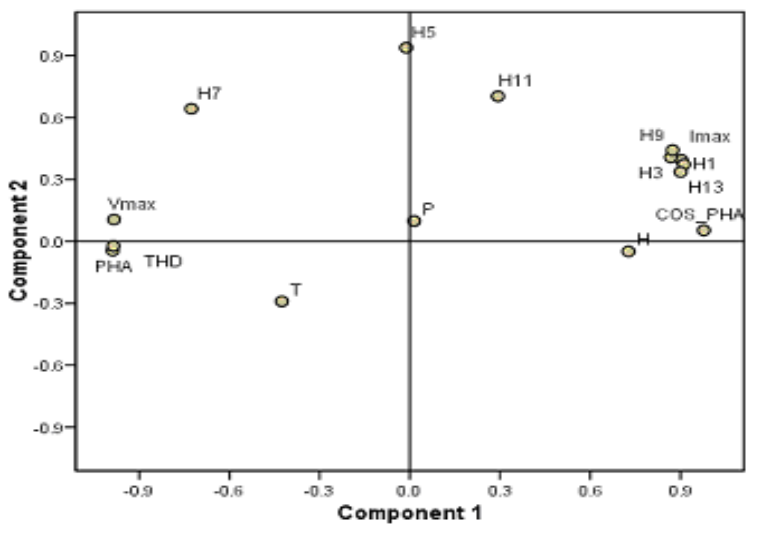

Figure 9. Scatter plot of first two principal components

On other hand, the applied voltage amplitude (Vmax) is very close to phase angle (PHA) and total harmonic distortion (THD). These are very considerable. Phase angle and THD are as consequence of relative humidity. The increment of humidity would cause to reduce the phase angle and THD. These phenomena indicate that the polluted insulator would be more resistive, rather than capacitive. The leakage current waveform also tended to approach the pure sinusoidal waveform, so that THD would reduce. Other little bit technical support, the applied voltage amplitude rose, the insulator would be more capacitive. This is common for almost high voltage equipment, i.e. the capacitive property will be more 
visible for higher applied voltage amplitude. Consequently, the phase difference between leakage current and applied voltage waves will increase. Besides that, the consequent of capacitive increment is also the increasing of harmonic content. This is indicated by THD, that it would rise as the phase angle increased.

Pressure (P) occupy a point that close to the zero point of coordinate, and relative far from other parameters. This indicates that pressure was low dependency to other parameters.

Figure 10 shows the scatter plot of first three principal components. On this scatter plot, the extracted information is $86.46 \%$. This is higher than previous one. The power factor is closer to the relative humidity. This is proof that the relative humidity influence to power factor very significantly.

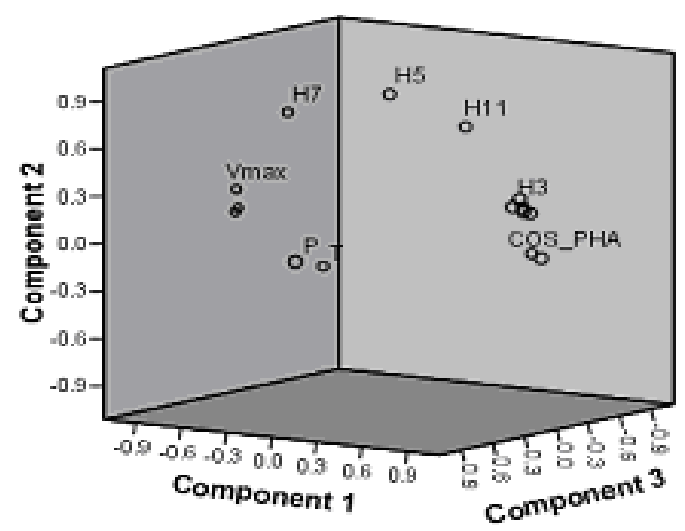

Figure 10. Scatter plot of first three principal components

Little bit further from the power factor, there are leakage current amplitude and the previous certain harmonics (H1, H3, H9, H13). These parameters were also influenced by relative humidity considerably. Otherwise, the phase angle is also opposite of power factor and relative humidity. This means, the phase angle would reduce as the relative humidity increased. Besides that, the phase angle and THD are close to applied voltage amplitude. These phenomena support the previous first two principal component analysis. Thoroughly, the principal component analysis supports the previous of correlation coefficient matrix.

\section{CONCLUSION}

On the polluted porcelain insulator, the humidity influenced to both leakage current magnitude and phase angle very significantly. This was higher than applied voltage, although the leakage current existence due to applied voltage. This was triggerred by coastal pollutant stuck on the porcelain insulator surface.
As addition, the total harmonic distortion would reduce as the relative humidity increased. Thus, the high relative humidity made the polluted porcelain insulator would be more resistive rather than capacitive.

Generally, the leakage current reduced as the temperature rose, due to relative humidity decreased. In this range, the pressure did not influence to leakage current magnitude and phase angle practically. The most harmonics were high correlated to leakage current magnitude.

\section{REFERENCES}

[1] Fernando, M.A.R. Manjula, supervised by Gubanski, Performance for Non-ceramic Insulators in Tropical Environments, $\mathrm{PhD}$ Dissertation, Department of Electric Power Engineering, Chalmers University of Technology, Goteborg-Sweden, pp.1-2, 1999.

[2] Vosloo, Wallace L., supervised by Holthhausen, A Comparison of the Performance of HighVoltage Insulator Materials in a Severely Polluted Coastal Environment, PhD Dissertation, Department of Electrical and Electronic Engineering, University of Stellenbosch, South Africa, March, pp.9-10, 2002.

[3] Gorur, R.S., Cherney, E.A., Burnham, J.T., Outdoor Insulators, Ravi S. Gorur, Inc., Phoenix, Arizona, USA, pp.145, 1999.

[4] Vosloo, W.L., Macey, R.E., Toureil, C. de, The Practical Guide to Outdoor High Voltage Insulators, Crown Publications CC., Johannesburg, South Africa, pp.36-37, 2004.

[5] Suwarno, "Leakage Current Waveforms of Outdoor Polymeric Insulators and Possibility of Application for Diagnostics of Insulator Conditions", Journal of Electrical Engineering \& Technology, The Korean Institute of Electrical Engineering, Vol.1,No.1,pp.114-119, 2006.

[6] OriginLab Co., Origin V75 User's Manual, OriginLab Corporation, MA,USA, pp.601-611, 2003.

[7] Anderson, T.W., An Introduction to Multivariate Statistical Analysis, Second Edition, John Wiley \& Sons, pp.18,489, 1984.

[8] Whittaker, J., Graphical Models in Applied Multivariate Statistics, John Wiley \& Sons, pp.17,48-51, 1996.

[9] Hannawati A., Thiang, Prasetyo Y., Odor Recognition dengan Menggunakan Principal Component Analysis dan Nearest Neighbour Classifier, http:// puslit.petra.ac.id/ journals/ electrical, accessed on $1^{\text {st }}$ Dec. 2007. 
[10] Mardia, K.V., Kent, J.T., Bibby, J.M., Multivariate Analysis, Academic Press, London, UK, pp.213-228, 2000.
[11] Lab. Perencanaan dan Optimasi Sistem Industri, Handout multivariate Analysis, Seminar and Workshop, Teknik Industri ITB, $17^{\text {th }} \& 24^{\text {th }}$ March, 2007. 